\title{
The Making of Compassion Stress Injury: A Review of Historical and Etiological Models toward a De-Stigmatizing Neurobehavioral Conceptualization
}

\author{
Mark Russell * and Jessica Cowan \\ Clinical Psychology Psy.D. Program, Antioch University Seattle, 2326 Sixth Avenue, Seattle, WA 98121-1814, \\ USA; jcowan@antioch.edu \\ * Correspondence: mrussell@antioch.edu; Tel.: +1-206-268-4837; Fax: +1-206-441-3307
}

Received: 19 December 2017; Accepted: 23 February 2018; Published: 26 February 2018

\begin{abstract}
The complex interactions between empathy and vulnerability amongst those in helping professions/roles have been explored by practitioners and researchers across multiple disciplines for decades. While these explorations have spurred interest and awareness in the unique risks and protective factors of helping professions/roles, they have also resulted in myriad competing, overlapping, and/or parallel definitions, conceptualizations, terminology, and etiological attributions of adverse impacts of secondary exposure to others' suffering. In this conceptual review, we will follow the historical origins of this phenomenon, beginning with the early 1900s with the First World War and the works of early psychiatric clinicians and moving toward recent advances in understanding etiology and conceptualization. Finally, we will provide support for the use and additional research of a proposed unifying and comprehensive conceptualization term: compassion stress injury (CSI), based on a mind-body and de-stigmatizing framework.
\end{abstract}

Keywords: compassion fatigue; empathy; stress injury; burnout; vicarious trauma; compassion stress injury

\section{Introduction}

\subsection{Overview of Compassion Stress Injury (CSI)}

Since as early as biblical times, literature has pointed toward the potential negative consequences of working with distressed and/or traumatized individuals, often using labels of "compassion fatigue" and "secondary trauma" [1-16]. These consequences have been conceptualized across risk and protective domains, eluding to both the positive and/or adverse outcomes that can be associated with secondary exposure to trauma $[1,16-18]$. While evidence exists for the potential protective components of working in helping professions, large portions of research have expanded our awareness of possible adverse effects including the prevalence of helping professionals to experience trauma-related symptomology [1-8]. These symptoms often mirror the unwanted symptoms of their clients/patients, including intrusive thoughts/images and physiological changes in brain and other organ systems $[2,3,8-18]$.

\subsection{Overview of CSI Terminology}

Multiple terms, including vicarious trauma, secondary trauma, and compassion fatigue, have been used to describe the adverse responses to exposure to the suffering of others $[1-3,15-18]$. These terms often reflect the historical, cultural, and/or contextual factors prevalent during the time of their conceptualization and have been debated by experts across multiple disciplines for 
their clinical, cultural, and/or political relevance [1]. As a way of unifying these definitions, and to better address emerging evidence for the biopsychosocial processes and outcomes associated with this phenomenon, we propose the use of the term compassion stress injury (CSI), which will be used throughout this article [1]. Our assertion of CSI is intended to convey an actual mind-body "wounding" not dissimilar to physical injury versus mere fatigue or other abstraction $[1,19,20]$. This conceptualization follows recent efforts by military groups around the world to avoid stigmatizing terminology including the U.S. military dropping the " $\mathrm{D}$ " in post-traumatic stress disorder (PTSD) to embrace post-traumatic stress (PTS); the Canadian Armed Forces (CAF) adopting the term "operational stress injuries"; and the Israel Defense Forces (IDF) considering PTS (I-injury) versus PTSD [19,20]. These changes and ongoing debates have sparked heated medico-legal and political discourse about the authenticity of psychological wounds compared to physical injuries [20]. Actual evidence supporting the neuroscientific basis of CSI was reviewed in previous work and is beyond our purpose [1]. Instead, in this article, to better inform future directions for research, policy, and treatment, we will trace the historical conceptualizations and definitions associated with our evolving understandings of the impacts of exposure to the traumatic experiences of others.

\subsection{Prevalence of CSI}

Research has found that the prevalence of CSI amongst helping professionals is notable: $40-80 \%$ across various occupations, including therapists, police officers, military psychologists, emergency department workers, child welfare workers, hospice care providers, and other people working with vulnerable and/or traumatized populations, suffer from CSI [15-25]. Because of this high prevalence, it is important for us to understand the historical origins and contemporary understandings of CSI to inform interventions and research aimed at increasing the resiliency and protection of this population, whose work is invaluable across multiple fields.

\section{Overview of Conceptualizations and Etiological Models of CSI}

Mental health professionals have been exploring the linkages between stress, trauma, and neurobiological effects since the early 1900s [2]. Much of the work originated with Walter B. Cannon, an American Army psychiatrist of World War I (WWI) who first conceptualized the phrase "fight or flight" to explain why even the most resilient soldiers succumbed to shell shock [2]. These and other early explorations indicated that stress injuries were correlated with sudden physiological, neurological, and/or psychological changes in otherwise healthy individuals and that the consequences were often long-term, included observable changes in multiple organ systems, and greatly impacted the individual's functioning and overall wellbeing [3-8,11]. Relatedly, initial recognition of CSI was first observed in WWI under the term "shell shock by proxy", a phrase that originated based on the work of William H. R. Rivers, a British WWI Army psychiatrist at Craiglockhart War Hospital who began to exhibit symptoms that paralleled those of the stress-injured soldiers he was treating [10]. Important, albeit ignored, lessons of WWI consisted in the inevitability of psychiatric breakdown from chronic stress exposure irrespective of one's premorbid resilience and irrespective of whether first-or-second hand exposure-contradicting previous therapeutic models $[9,10]$.

Tragically, WWI trauma lessons about the universal nature and cause of war stress injury and CSI were roundly ignored. The chief psychiatric lesson arising from WWII was re-learning the inherent vulnerability to stress injury from sustained exposure: "Each moment of combat imposes a strain so great that men will break down in direct relation to the intensity and duration of their exposure. Thus, psychiatric casualties are as inevitable as gunshot and shrapnel wounds in warfare" [26] (p. 185). Consequently, the U.S. Army adopted euphemisms like battle fatigue and combat exhaustion to de-pathologize universal human responses to extreme stress and convey treatability of stress injuries, precursors to the modern-day "compassion fatigue". It also soon become apparent that those in these helping roles were also experiencing a type of stress injury related to secondary, and repeated, exposure to the traumatic experiences shared by those they served [9]. For example, U.S. Army psychiatrist 
Albert J. Glass reflected on the work of another U.S. Army psychiatrist Raymond Sobel who first coined the terms "old sergeant's syndrome" and "burnt out" to describe his observations of service members whose rank and experience led to a kind of stress injury associated with intersections of prolonged exposure to life/death decision making and serving as surrogate caregivers for those who served under them [11,12]. To this, Dr. Glass added concerns that psychiatrists serving traumatized populations were also likely to experience a kind of "old psychiatrist syndrome", and he proposed that those who found themselves emotionally affected by their patients should step back from their work for a time [11]. The WWII lessons of war trauma had a profound impact on transforming American mental healthcare, emphasizing prevention, early intervention, and treatability of mental illness in stark contrast to prevailing fatalistic attitudes emphasizing institutionalization [27].

\section{Compassion Stress Injury beyond the Military: Early Psychology and Contemporary Expansions}

In 1910, Freud alluded to CSI factors in his conceptualization of countertransference, a term he used to describe the potential for the patient to influence the feelings and unconscious experiences of the physician [13]. In 1992, Herman would expand Freud's work to point specifically to "traumatic counter-transference" to explain therapists' internal responses to patients' trauma narratives as a result of having revived "any personal traumatic experiences" [14] (p. 140). Herman theorized that, as a result, the therapist may struggle with similar difficulties as the client, and that empathic involvement of the therapist with the client would leave the therapist vulnerable [14]. In essence, Herman proposed that "trauma is contagious" [14] (p. 140).

McCann and Pearlman later derived their own conceptualization of vicarious traumatization (VT) that went beyond Herman's assertions that listening to trauma narratives may bring up therapists' own trauma experiences [15]. Instead, they proposed that clinicians could be affected even if the material was unrelated to their own personal experience [15]. These assertions broadened the potential of VT as a phenomenon that could impact previously un-traumatized clinicians [15]. Subsequent findings pointed to correlations between exposure to trauma narratives, and risks for clinicians to experience intrusive thoughts and/or imagery prompted by the narratives that could persist even after client contact had ended [16,17]. To explain the etiology of VT, McCann and Pearlman proposed a cognitive schema model, which asserted that compassion stress injuries were the result of alterations to the helping professional's existing schemas as a reaction to the trauma narrative [18]. These schema alterations were categorized across seven primary domains: frame of reference, safety, trust/dependency, independence, esteem, power, and/or intimacy [18].

Sobel's 1947 concept of "burnt out" in the military was expanded on by the works of Freudenberger and Maslach [12,21]. They respectively conceptualized the term of professional burnout (PB) and provided a definition: "emotional exhaustion, depersonalization, and reduced accomplishment" to explain symptoms experienced by civilian workers in the 1970s-1980s [12,21] ([22] p. 3). While PB was not initially conceptualized specifically for those in helping professions, it is considered a prevalent factor of CSI due to both the inherent personal nature of the work, and the vulnerable and/or traumatized populations that are often served [23,24]. Recent meta-analysis supports the strong co-occurrence of burnout and secondary traumatic stress amongst those working with traumatized individuals [25].

Secondary traumatic stress (STS) was introduced by psychologist Charles R. Figley, a veteran of the Vietnam War, who in 1978 expanded on earlier conceptualizations of CSI to include secondary experiences of both helping professionals and family members caring for military service members returning from the Vietnam War [28]. Figley was the first to propose a clinical definition of CSI in his description of STS as follows: "The natural consequent behaviors and emotions resulting from knowing about a traumatizing event experienced by a significant other-the stress resulting from helping or wanting to help a traumatized or suffering person" [29] (p. 7). Figley was also the first to explore the precedents for related phenomena of female partners of veterans, including folie a deux or "shared psychotic disorder" [29], "co-victimization" [29], "secondary survivor" [29], "rape-related 
family crisis" [29], and "proximity effects" [28,30]. Figley's work led to interest in intergenerational transmission of trauma in non-traumatized children and transgenerational trauma within families of Jewish holocaust survivors; both extensions of Figley's work have revealed the potential for unresolved STS as an explanation for the presentations of trauma-associated symptomology in otherwise un-traumatized populations [29,31-36]. In exploring the potential etiology of STS, Figley proposed a ten-factor causal model that addressed risk for STS across cognitive and emotional factors including the therapist's empathetic ability, concern, response, and exposure to explain STS experiences among those in helping professions [37].

Compassion fatigue (CF) was introduced in 1992 through the work of Carla Joinson who studied burnout amongst nurses in emergency departments and found relationships between earlier definitions of professional burnout and Figley's secondary traumatic stress [30,38]. Joinson asserted that experiences of burnout presented specifically by those in helping professions were better explained as a response to secondary trauma rather than occupational factors [30,38]. Joinson proposed that earlier terminology, including Figley's STS and McCann and Pearlman's VT, were potentially stigmatizing and may elicit perceptions that professionals were unable to cope with the inherent demands of their role, while fatigue was a less stigmatizing descriptor [38]. Figley later adopted the term compassion fatigue in his seminal text Compassion Fatigue: Coping with Secondary Traumatic Stress Disorder in Those Who Treat the Traumatized and elaborated on CF as "a state of tension and preoccupation with the traumatized patients by re-experiencing the traumatic events, avoidance/numbing of reminders persistent arousal (e.g., anxiety) associated with the patient. It is a function of bearing witness to the suffering of others" [30] (p. 1435). While both STS and CF are still used interchangeably, Figley and colleagues assert that STS is distinguished from CF in its broader application to populations beyond helping professions where compassion is an expected function [39].

As an alternative to $C F$ and $\mathrm{PB}$, empathetic distress fatigue (EDF) was proposed in 2012 by Klimecki and Singer based on their findings related to differences in the neurological correlates of compassionate and empathetic responses to observations of others' suffering [40,41]. These authors were the first to explore the neurological aspects of $\mathrm{CF}$ and $\mathrm{PB}$, and their findings suggest that empathy and compassion reactions are associated with two separate but corresponding neural pathways: (1) driven conscious/controlled, top-down, and other-oriented responses associated with the pre-frontal cortex and; (2) unconscious/automatic, bottom-up, self-oriented responses associated with the amygdala $[40,41]$. They further associated these neural activations with two categories of potential empathetic response to others' suffering: (1) compassion, empathic concern, and sympathy (e.g., conscious, executive functioning, other-related emotion, altruism, positive emotions, and motivation) $[40,41]$ and (2) empathic/personal distress (e.g., automatic, pain/threat, self-related emotion, negative feelings, withdrawal) $[40,41]$. They asserted the self-oriented empathetic response is causally related to $\mathrm{CF}$ and $\mathrm{PB}$ and thus proposed $\mathrm{EDF}$ as a better descriptor of these types of stress injuries [40,41]. Klimecki and Singer also asserted the importance of cognitive-control-based interventions to address EDF, proposing that increasing helping professionals' cognitive activation of compassionate, external, other-focused, responses to suffering that the authors proposed could serve a protective factor against automatic, negative internalized, responses to suffering [41].

More recently, as the result of a comprehensive review of the previously explored stress-injury conceptualizations, etiological models, neurophysiological findings, and de-stigmatizing linguistic considerations, we proposed the term "compassion stress injury" to better address the continuum and integrations of stress injuries represented in previous labels including CF, STS, and EDF [1]. CSI is a neurobehavioral model that unites the historical conceptualizations for explaining stress injuries in helping professions and the linguistic importance of compassion- and injury-oriented terminology, while also more coherently addressing the empirical findings of neurophysiological explanations for CSI, which we assert have been largely underrepresented in previous attempts to explain and conceptualize these stress injuries [1,8,40-44]. 
It is our assertion that neurophysiological explanations, including the activation of mirror neurons in empathetic processes and structural brain changes in response to CSI, are representative of the potentially injurious and biopsychosocially complex nature of this phenomenon [1,8,42-44]. Recent neurological findings demonstrate the basis of our ability to understand, feel, and physiologically respond to what another is feeling, often at an unconscious, automatic level, and the potential consequences of such abilities including increased vulnerability to stress injuries for those in helping professions [1,40-44]. Mirror neurons, and the mirror neuron system (MNS), are of particular interest in our conceptualization of CSI, related to the brain's ability to automatically initiate a kind of neural-mimicry in the observer, during observation of the behaviors and/or emotions of others [1,42].

Human research related to mirror-neurons and the MNS illustrates our ability to experience "mirrored" brain activations in response to a variety of stimuli, including exposure to the emotional experiences of others, with findings that suggest these mirrored neural activations can even parallel those expected during first-hand emotion experiences $[1,42,44]$. While the conceptualization of EDF is based in neurologically associated findings, it is, in our opinion, a limited representation of the correlates between neurophysiology and stress injuries in helping professionals. This critique is based on the emphasis in EDF on cognitive control as a primary protective factor, without addressing the impact of cumulative, automatic empathetic responses, and interactions of complex risk/protective factors asserted in past and present research including the conflicting neurological findings that distress responses are correlated with both withdrawal and helping behaviors [1,40-44]. In contrast, CSI takes into account the potential for the automatic impact of empathetic response, and the nature of that response as largely beyond awareness/control toward decreasing stigmatization, while also addressing myriad mediating biopsychosocial factors [1].

As previously stated, we proposed CSI to address the injurious nature of these trauma responses toward a reduction of both abstraction and stigmatization. Thus, the language for CSI was chosen for its Latin origins and literal translations of compassion as "to suffer with," and fully defined as "sympathetic consciousness of others' distress together with a desire to alleviate it." When combined with "stress" - "a physical, chemical, or emotional factor that causes bodily or mental tension and may be a factor in disease causation" — and "injury" - "an act that damages or hurts" (see Merriam-Webster at http: / / www.m-w.com) -we have the makings of CSI. Use of the word "injury" is also supported by scholars and clinicians who have sought to reduce the potential stigmatization caused by the use of "disorder" in diagnostic language, and the use of "injury" has been proposed, though not yet adopted, for use in the DSM-V [19]. While previous models have utilized "fatigue" in an effort to reduce stigmatization of those suffering from CSI, these and other euphemisms minimized the specific outcomes of compassion-related stress injury including structural changes in the brain and other organ systems that vary from the impacts of fatigue, and are unique to compassion and empathy $[1,8,40,41,43]$. In this way, CSI addresses the comprehensive physical, cognitive, emotional, and behavioral complexities of what is known about the risks and protective factors for those in helping professionals, while attending to the unique role of compassion $[1,17,25,39,40]$. It is important to note that the term CSI was first proposed in 2015, and it has not yet been adopted for diagnostic purposes [1].

\section{Conclusions}

CSI has a long history that includes multidisciplinary explorations and understandings of the unique impacts of empathetic understanding including adverse and positive effects spanning the history of traumatology and war stress injuries. Interest in CSI has resulted in the development of conceptualizations and etiological explanations since the early 1900s, leading to a more recent emergence of evidence to support the role of neural mechanisms and an integrated holistic approach to explaining empathetic experiences, and the unique role of compassion as a uniting factor to these types of stress injuries. While competing, and primarily dualistic, models of understanding CSI are 
still prevalent in the literature, our hope is that this examination of the past, combined with more recent empirical findings will continue to increase the acceptance and expansion of a more holistic examination of CSI in research and interventions. Of particular interest for future research would be the exploration of a multicultural understanding of the applicability and impact of CSI, including global political, economic, and contextual factors.

Author Contributions: Mark Russell conceived and designed the study and provided the preliminary write up. Jessica Cowan provided additional writing and editing.

Conflicts of Interest: The authors declare no conflict of interest.

\section{References}

1. Russell, M.; Brickell, M. The "Double-Edge Sword" of Human Empathy: A Unifying Neurobehavioral Theory of Compassion Stress Injury. Soc. Sci. 2015, 4, 1087-1117. [CrossRef]

2. Institute of Medicine. Treatment of Posttraumatic Stress Disorder: An Assessment of the Evidence; National Academies Press: Washington, DC, USA, 2008.

3. Russell, M.C.; Figley, C.F. Treating Traumatic Stress Disorders in Military Personnel: An EMDR Practitioner's Guide; Routledge: New York, NY, USA, 2013.

4. Cannon, W.B. “Voodoo" death. Amer. Anthropol. 1942, 44, 169-181. [CrossRef]

5. Samuels, M.A. "Voodoo" death revisited: The modern lessons of neurocardiology. Clevel. Clin. J. Med. 2007, 74, 88-816. [CrossRef]

6. Goodfriend, M.; Wolpert, E.A. Death from fright: Report of a case and literature review. Psychosom. Med. 1976, 38, 5. [CrossRef]

7. Seyle, H.; Fortier, C. Adaptive reaction to stress. Psychosom. Med. 1950, 12, 149-157. [CrossRef]

8. Bremner, J.D. Does Stress Damage the Brain? Understanding Trauma-Related Disorders from a Mind-Body Perspective; Norton: New York, NY, USA, 2005.

9. Nickerson, K.G.; Shea, S. WHR Rivers: Portrait of a Great Physician in Pat Barker's Regeneration Trilogy. Lancet 1997, 350, 205-209. [CrossRef]

10. Barker, P. Regeneration; Williams Abrahams Book Dutton: New York, NY, USA, 1991.

11. Glass, A.J. Psychiatry at the division level. In Combat Psychiatry; Experiences in the North African and Mediterranean Theaters of Operation, American Ground Forces, World War II; Hanson, F.R., Ed.; University Press: Honolulu, HI, USA, 1949; pp. 61-62.

12. Sobel, R. The "old sergeant" syndrome. Psychiatry 1947, 10, 315-321. [CrossRef] [PubMed]

13. Freud, S. The Future Prospects of Psycho-Analytic Therapy: Collected Papers; Hogarth Press: London, UK, 1910.

14. Herman, J. Trauma and Recovery; Basic Books: New York, NY, USA, 1992.

15. McCann, L.; Pearlman, L.A. Vicarious traumatisation: A framework for understanding the psychological effects of working with victims. J. Traumatic Stress 1990, 3, 131-149. [CrossRef]

16. Harrison, R.L.; Westwood, M.J. Preventing vicarious traumatization of mental health therapists: Identifying protective practices. Psychother. Theory Res. Pract. Train. 2009, 46, 203-219. [CrossRef] [PubMed]

17. Hesse, A.R. Secondary trauma: How working with trauma survivors affects therapists. Clin. Soc. Work J. 2002, 30, 293-309. [CrossRef]

18. Horowitz, M.J. Essential Papers on Post Traumatic Stress Disorder; New York University Press: New York, NY, USA, 1999.

19. Keynan, I.; Keynan, J.N. War Trauma, Politics of Recognition and Purple Heart: PTSD or PTSI? Soc. Sci. 2016, 5, 57. [CrossRef]

20. Russell, M.; Schaubel, S.; Figley, C. The darker side of military mental healthcare part two: Five harmful strategies to manage its mental health dilemma. Psychol. Inj. Law 2018, 18, 1-32. [CrossRef]

21. Freudenberger, H.J. Staff burn-out. J. Soc. Issues 1974, 30, 159-165. [CrossRef]

22. Maslach, C. Burnout-The Cost of Caring; Prentice-Hall: Englewood Cliffs, NJ, USA, 1982.

23. Wee, D.; Myers, D. Response of mental health workers following disaster: The Oklahoma City bombing. In Treating Compassion Fatigue; Figley, C.R., Ed.; Brunner/Rutledge: New York, NY, USA, 2002.

24. Imai, H.; Nakao, H.; Tsuchiya, M.; Kuroda, Y.; Katon, T. Burnout and work environments of public health nurses involved in mental health care. Occup. Environ. Med. 2004, 61, 764-768. [CrossRef] [PubMed] 
25. Cieslak, R.; Shoji, K.; Douglas, A.; Melville, E.; Luszczynska, A.; Benight, C.C. A meta-analysis of the relationship between job burnout and secondary traumatic stress among workers with indirect exposure to trauma. Psychol. Serv. 2014, 11, 75. [CrossRef] [PubMed]

26. Appel, J.; Beebe, G. Preventive psychiatry; An epidemiologic approach. J. Am. Med. Assoc. 1946, 131, 1469-1475. [CrossRef] [PubMed]

27. Russell, M.C.; Figley, C.R. Overview of the Affordable Care Act's impact on military and veteran mental health services: Nine implications for significant improvements in care. J. Soc. Work Disab. Rehabil. 2014, 13, 162-196. [CrossRef] [PubMed]

28. Figley, C.R. Stress Disorders among Vietnam Veterans; Brunner/Mazel: New York, NY, USA, 1978.

29. Figley, C.R. Catastrophes: An overview of family reactions. In Stress and the Family, Vol. II: Coping with Catastrophe; Figley, C.R., McCubbin, H.I., Eds.; Brunner/Mazel: New York, NY, USA, 1983; pp. 3-20.

30. Figley, C.R. Compassion fatigue as secondary traumatic stress disorder: An overview. In Compassion Fatigue: Coping with Secondary Traumatic Stress Disorder in those Who Treat the Traumatized; Brunner/Mazel: New York, NY, USA, 1995; pp. 1-20.

31. National Institute of Mental Health (U.S.); Center for Mental Health Studies of Emergencies (U.S.). Disaster Work and Mental Health: Prevention and Control of Stress among Workers; Hartsough, D.M., Myers, D.G., Eds.; National Institute of Mental Health: Rockville, MD, USA, 1985.

32. Remer, R.; Elliott, J.E. Characteristics of secondary victims of sexual assault. Int. J. Fam. Psychiatry 1988, 9 , 373-387.

33. Erickson, C.A. Rape and the family. In Treating Stress in Families; Figley, C.R., Ed.; Brunner/Mazel: New York, NY, USA, 1989.

34. Verbosky, S.J.; Ryan, D.A. Female partners of Vietnam veteran: Stress by proximity. Issues Ment. Health Nurs. 1988, 9, 95-104. [CrossRef] [PubMed]

35. Rosenheck, R.; Nathan, P. Secondary traumatization in children of Vietnam veterans. Hosp. Commun. Psychiatry 1985, 36, 538-549. [CrossRef]

36. Danieli, Y. The treatment and prevention of long-term effects and intergenerational transmission of victimization: A lesson from Holocaust survivors and their children. In Trauma and Its Wake; Figley, C.R., Ed.; Brunner/Mazel: New York, NY, USA, 1985; pp. 295-313.

37. Figley, C.R. Compassion fatigue: Psychotherapists' chronic lack of self care. J. Clin. Psychol. 2002, 58, 1433-1441. [CrossRef] [PubMed]

38. Joinson, C. Coping with compassion fatigue. Nursing 1992, 22, 116-121. [PubMed]

39. Ludick, M.; Figley, C.R. Toward a mechanism for secondary trauma induction and reduction: Reimagining a theory of secondary traumatic stress. Traumatology 2017, 23, 112. [CrossRef]

40. Klimecki, O.; Singer, T. Empathic distress fatigue rather than compassion fatigue? Integrating findings from empathy research in psychology and social neuroscience. In Pathological Altruism; Oakley, B., Knafo, A., Madhavan, G., Wilson, D.S., Eds.; Oxford University Press: New York, NY, USA, 2015; pp. 368-383.

41. Klimecki, O.; Leiberg, S.; Ricard, M.; Singer, T. Differential Pattern of Functional Brain Plasticity after Compassion and Empathy Training. Soc. Cogn. Affect. Neurosci. 2014, 9, 873-879. [CrossRef] [PubMed]

42. Molenberghs, P.; Cunnington, R.; Mattingley, J.B. Brain regions with mirror properties: A meta-analysis of 125 human fMRI studies. Neurosci. Biobehav. Rev. 2012, 36, 341-349. [CrossRef] [PubMed]

43. Soto-Rubio, A.; Sinclair, S. In defence of sympathy, in consideration of empathy, and in praise of compassion: A history of the present. J. Pain Symptom Manag. 2017. [CrossRef] [PubMed]

44. Ashar, Y.K.; Andrews-Hanna, J.R.; Dimidjian, S.; Wager, T.D. Empathic care and distress: Predictive brain markers and dissociable brain systems. Neuron 2017, 94, 1263-1273. [CrossRef] [PubMed]

(C) 2018 by the authors. Licensee MDPI, Basel, Switzerland. This article is an open access article distributed under the terms and conditions of the Creative Commons Attribution (CC BY) license (http:/ / creativecommons.org/licenses/by/4.0/). 